\title{
Modelling of the Eutectoid Reaction in Spheroidal Graphite Fe-C-Si Alloys
}

\author{
Jacques LACAZE and Valérie GERVAL \\ Laboratoire des Matériaux, ENSCT, UPRESA-CNRS 5071, 31077 Toulouse cedex, France. E-mail: jlacaze@ensct.fr
}

(Received on December 1, 1997; accepted in final form on March 3, 1998)

\begin{abstract}
The so-called eutectoid reaction of spheroidal graphite cast irons (SGI) proceeds by competitive nucleation and growth of ferrite and pearlite. In the present study are first reviewed the physical models of the ferritic reaction in SGI previously described in the literature. Then, a new model is presented that uses a recent description of the conditions to be fulfilled for the ferritic and pearlitic reactions to start. This description is based upon the knowledge of the relevant phase diagram. Growth of the ferrite halos during the ferritic reaction is described as controlled by carbon transfer from the austenite/ferrite interface to the graphite nodules and by an interfacial reaction at the ferrite/graphite interface. Modelling of the pearlitic reaction accounts for nucleation of pearlite colonies, and their growth law is expressed according to experimental data available in the literature. It appeared also necessary to describe the diffusion of carbon in austenite before the beginning of the decomposition of this phase. Predictions are compared to experimental transformation kinetics obtained by means of differential thermal analysis on spheroidal graphite $\mathrm{Fe}-\mathrm{C}-\mathrm{Si}$ alloys, and could be easily extended to alloys with low level additions of pearlite promoter elements.
\end{abstract}

KEY WORDS: spheroidal graphite cast irons; Fe-C-Si alloys; eutectoid reaction; transformation kinetics; physical modelling.

\section{Introduction}

Spheroidal graphite cast irons (SGI) are made of graphite nodules embedded in an iron base matrix. The most common types of these alloys are mainly $\mathrm{Fe}-\mathrm{C}-\mathrm{Si}$ ternary alloys, with low level of $\mathrm{Mg}$ added as a nodularizer. The matrix is austenitic at high temperature; upon cooling to room temperature after solidification or heat treatment, austenite decomposes either to ferrite and graphite (in the stable system), or to pearlite (in the metastable system), or else to both of them. The control of the actual microstructure of the material at room temperature is of some importance as the number of nodules and the ratio of the ferrite and pearlite fractions determine the service properties of the cast components. ${ }^{1)}$ It seems established that higher nodule counts and lower cooling rates (in the temperature range of the eutectoid transformation) both favor the decomposition of austenite in the stable system. ${ }^{2)}$ On the other hand, adding low level of specific elements such as $\mathrm{Cu}, \mathrm{Mn}, \mathrm{Sn}$ or $\mathrm{Sb}$, is a practical means to obtain a pearlitic matrix. ${ }^{3-5}$ The ferrite to pearlite ratio also depends, but to a lesser extent, on microsegregation, i.e. chemical heterogeneities at the level of the microstructure, which build up during the solidification stage. $^{6-8)}$ Finally, in case of heat treatment, the austenitizing temperature affects the eutectoid reaction because of the change of the solubility of carbon content in the parent austenite with temperature. ${ }^{9)}$
The effects of nodule count, of the cooling rate (in the range 1 to $20 \mathrm{~K} / \mathrm{min}$ ), and of low level addition of $\mathrm{Mn}$ and/or $\mathrm{Cu}$, have been studied previously by differential thermal analysis (DTA). ${ }^{10)}$ The characteristic temperatures at the beginning of the transformation, in the stable and metastable systems, as well as the kinetics of austenite decomposition, were evaluated from the DTA signal. It was observed that the decomposition of austenite starts at a temperature which is well below the upper limit of the triphasic austenite/ferrite/graphite or austenite/ferrite/cementite domain. For both the stable and metastable transformations, the undercoolings observed were of the same magnitude than those reported by Ekpoom and Heine ${ }^{11)}$ who used also DTA. In order to deepen the understanding of the solid-state transformation of SGI, a second series of experiments was carried out with samples which were held $1 \mathrm{~h}$ at $1100^{\circ} \mathrm{C}$ so as to smooth out microsegregations. ${ }^{12)}$ Such a treatment did in fact eliminate the extrema of the solute distributions rather than actually homogenize the matrix. The transformation temperatures were slightly modified with respect to the untreated material, but the effect of the cooling rate on the transformation kinetics remained unchanged.

From the experimental fact that growth of ferrite during cooling of SGI is not associated with partitioning of substitutionnal elements ( $\mathrm{Si}, \mathrm{Cu}, \mathrm{Mn}, \cdots$ ) between ferrite and austenite, we proposed to follow the decomposition of austenite in the stable system in an 


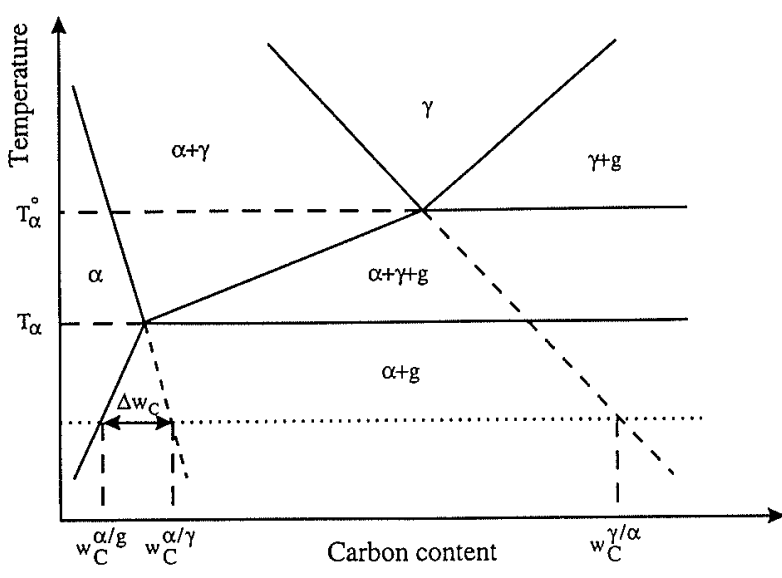

Fig. 1. Schematic isopleth $\mathrm{Fe}-\mathrm{C}$ section of the relevant stable phase diagram in the temperature range corresponding to the eutectoid reaction. Solid lines represent the limits of the phase fields and broken lines the metastable extrapolation of the ferrite/austenite $(\alpha / \gamma)$ and austenite/ferrite $(\gamma / \alpha)$ boundaries

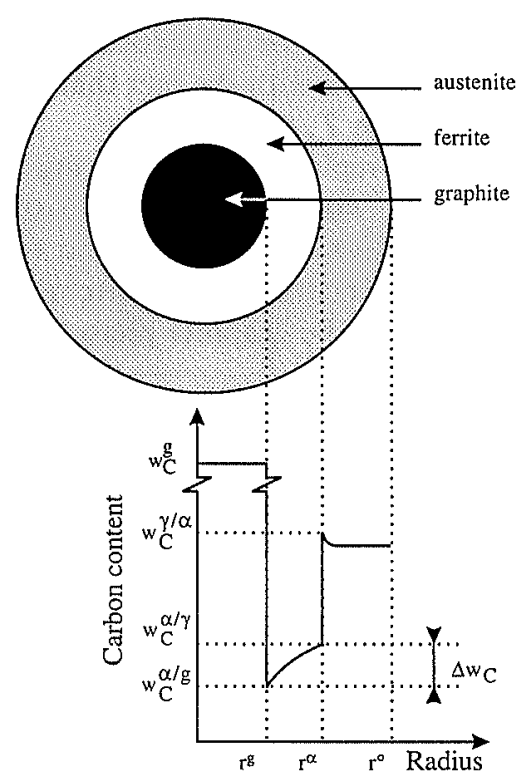

Fig. 2. Schematic representation of the relevant volume element and of the carbon distribution during the socalled ferritic decomposition of austenite.

$\mathrm{Fe}-\mathrm{C}$ isopleth section of the relevant phase diagram as illustrated in Fig. 1. ${ }^{12,13)}$ In most cases, ferrite nucleates at the graphite/austenite interface and then grows as halos around the nodules. This reaction will be called the ferritic reaction in the following. It is generally accepted that this reaction is controlled by transfer of carbon from the austenite/ferrite interface to the graphite nodules which act as carbon sinks. The relevant volume element to describe the decomposition of austenite is a sphere as illustrated in Fig. 2. It has a graphite nodule at its centre surrounded by a ferrite halo while the remaining volume is made of untransformed austenite. The carbon distribution at the level of the microstructure is also indicated under Fig. 2. For diffusion of carbon to proceed through the ferrite halo, the quantity $\Delta w_{\mathrm{C}}=w_{\mathrm{C}}^{\alpha / \gamma}-w_{\mathrm{C}}^{\alpha / g}$ must be positive (it should be noted that using the composition is equivalent to using the chemical potential in this case). Figure 1 indicates that this condition is verified only when the temperature of the material is below the lower temperature of the triphasic domain, named $T_{\alpha}$ in the following. Using the temperature $T_{\alpha}$ as the reference temperature for the ferritic reaction, it was found that the undercooling increases with the cooling rate, as expected, and drops to zero when the data is extrapolated to a zero cooling rate. ${ }^{12,13)}$ This latter observation gives some confidence to the above description of the growth conditions during the ferritic reaction.

A nearly similar reasoning was applied to the formation of pearlite on the basis that no redistribution of substitutional elements between pearlite and austenite has been reported in the case of cast irons. This leads to the condition that pearlite cannot grow at temperatures higher than the lower limit of the corresponding threephase austenite/ferrite/cementite field. ${ }^{12)}$ The reference temperature for the beginning of the pearlitic reaction, named $T_{p}$, was selected as the intersection of the $\gamma / \alpha$ extrapolation with this limit. In addition, it is expected that pearlite grows in SGI as it does in steels. Thus, it is worth mentioning that the model for isothermal transformation of austenite to pearlite developed by Hillert ${ }^{14)}$ has been applied satisfactorily by Tewari and Sharma ${ }^{15)}$ to the $\mathrm{Fe}-\mathrm{C}-\mathrm{Si}$ steel investigated by Al Salman et al. ${ }^{16)}$ The results of these authors could be used as reference data for the growth of pearlite in cast irons. In particular, it is worth noting that the undercoolings experienced for the onset of the pearlite growth in SGI were observed to be of the same order than the undercooling reported for isothermal reaction in $\mathrm{Fe}-\mathrm{C}-\mathrm{Si}$ steel. ${ }^{12,13)}$

In this study are first reviewed the models of the ferritic reaction previously described in the literature. Then a new model is presented which takes into account the above mentioned conditions of the growth of ferrite and pearlite. The description of the pearlitic transformation is made on the basis of the results of Al Salman et al. ${ }^{16)}$ Finally, the necessary input data and the few physical parameters for which no values are available in the literature are selected and predictions are compared with transformation kinetics deduced from DTA experiments. The present model is limited to $\mathrm{Fe}-\mathrm{C}-\mathrm{Si}$ alloys but will be extended in a near future to account for the effect of usual alloying elements $(\mathrm{Cu}, \mathrm{Mn}, \mathrm{Cr}, \cdots)$.

\section{Review of the Previous Modelling Approaches of the Ferritic Reaction}

As pointed out by Venugopalan, ${ }^{17)}$ the decomposition of austenite in the stable system to give ferrite plus graphite is much alike isothermal ferritization. Since the work of Brown and Hawkes, ${ }^{18)}$ it is agreed that isothermal ferritization of SGI is essentially controlled by carbon diffusion to the graphite through the ferrite shells which develop around the graphite nodules. In practice, the material is divided in equally sized units with an equivalent radius $r^{\circ}$ deduced from the nodule count per unit volume, $N_{\mathrm{V}}^{\mathrm{o}}$ (see Fig. 2):

$$
r^{\circ}=\left(\frac{3}{4 \pi N_{\mathrm{V}}^{0}}\right)^{0.333}
$$


Venugopalan ${ }^{19)}$ summarized the main steps of the isothermal decomposition of austenite to ferrite and graphite as follows:

(1) nucleation of ferrite occurs at the austenite/ graphite interface. An incubation period is associated with this step which is attributed to the limited kinetics of nucleation. In his study, Venugopalan considered that the incubation period actually corresponds to the time at which a ferrite nucleus has formed and has grown to an observable volume fraction, typically $1 \%$. The author pointed out that the development of this nucleus is attended by diffusion of carbon in the parent austenite. However, for modelling purpose, Venugopalan assumed that all the nodules are instantaneously surrounded by a ferrite shell when the incubation time is reached. The thickness of this shell is such that the volume fraction of ferrite is equal to the initial value chosen.

(2) growth of ferrite is attended by rejection of carbon which diffuses to the graphite nodules and into untransformed austenite. The mass conservation condition for carbon at the austenite-ferrite interface is given by:

$$
\rho^{\alpha}\left(w_{\mathrm{C}}^{\gamma / \alpha}-w_{\mathrm{C}}^{\alpha / \gamma}\right) \frac{d r^{\alpha}}{d t}=\rho^{\alpha} D_{\mathrm{C}}^{\alpha}\left|\frac{\partial w_{\mathrm{C}}^{\alpha}}{\partial r}\right|_{r^{\alpha}}-\rho^{\gamma} D_{\mathrm{C}}^{\gamma}\left|\frac{\partial w_{\mathrm{C}}^{\gamma}}{\partial r}\right|_{r^{\alpha}}
$$

where $\rho^{\varphi}$ is the density of phase $\varphi$ (either ferrite: $\alpha$ or austenite: $\gamma), D_{\mathrm{C}}^{\varphi}$ is the diffusion coefficient of carbon in phase $\varphi, w_{\mathrm{C}}^{\gamma / \alpha}$ and $w_{\mathrm{C}}^{\alpha / \gamma}$ are the mass fraction of carbon respectively in austenite and in ferrite at the austenite/ ferrite interface, $w_{C}^{\varphi}$ is the mass fraction of carbon in phase $\phi$, and $r^{\alpha}$ is the radius of the ferrite envelop.

The growth rate of the graphite nodule is given by the carbon mass balance at the ferrite-graphite interface:

$$
\rho^{\mathrm{g}}\left(1-w_{\mathrm{C}}^{\alpha / \mathrm{g}}\right) \frac{d r^{\mathrm{g}}}{d t}=\rho^{\alpha} D_{\mathrm{C}}^{\alpha}\left|\frac{\partial w_{\mathrm{C}}^{\alpha}}{\partial r}\right|_{r^{\mathrm{g}}}
$$

where $w_{\mathrm{C}}^{\alpha / g}$ is the mass fraction of carbon in ferrite at the ferrite/graphite interface and $r^{\mathrm{g}}$ is the radius of the graphite nodule.

It is generally accepted that diffusion of carbon through the ferrite shell may be expressed as a stationary process, i.e. that it is possible to express the carbon profile in the ferrite halo as $w_{\mathrm{C}}^{\alpha}=a+b / r$, where the constants $a$ and $b$ are to be determined from the value of the carbon content in the ferrite halo at the two limiting interfaces. This gives for the gradient in carbon content in ferrite ${ }^{19)}$ :

$$
\left|\frac{\partial w_{\mathrm{C}}^{\alpha}}{\partial r}\right|_{r_{\mathrm{g}}^{\mathrm{g}}}=\frac{r^{\alpha} \Delta w_{\mathrm{C}}}{r^{\mathrm{g}}\left(r^{\alpha}-r^{\mathrm{g}}\right)} \text { and }\left|\frac{\partial w_{\mathrm{C}}^{\alpha}}{\partial r}\right|_{r^{\alpha}}=\frac{r^{\mathrm{g}} \Delta w_{\mathrm{C}}}{r^{\alpha}\left(r^{\alpha}-r^{\mathrm{g}}\right)} \ldots
$$

The redistribution of carbon in the parent austenite was considered by Venugopalan using the so-called Zener's approximation and it was found that diffusion in austenite has a negligible effect during the ferritic reaction. This author has also extended his approach to treat the decomposition of austenite to ferrite and graphite and to pearlite during continuous cooling of the material. The only change to the above description is that the incubation time was then calculated by using the so-called "additivity rule". In a further development, ${ }^{20)}$ Venugopalan suppressed the contribution of carbon diffusion in austenite in Eq. (2), leaving everything else unchanged. The growth rate of the ferrite shell was then given by:

$$
\left(w_{\mathrm{C}}^{\gamma / \alpha}-w_{\mathrm{C}}^{\alpha / \gamma}\right) \frac{d r^{\alpha}}{d t}=D_{\mathrm{C}}^{\alpha}\left|\frac{\partial w_{\mathrm{C}}^{\alpha}}{\partial r}\right|_{r^{\alpha}}
$$

Equation (5) is similar to the equations previously derived in the works devoted to isothermal ferritization. ${ }^{18,21)}$

The models developed by Chang et al. ${ }^{22)}$ and by Svensson et al ${ }^{23)}$ are very much alike the model of Venugopalan ${ }^{20)}$ but the three following points:

(1) nucleation of ferrite is instantaneous, it occurs at a temperature which has to be experimentally determined. Chang et al. made use of DTA records while Svensson and Wessén used the line defining the start of the transformation on the CCT diagram of their material. These two methods appear to be very similar to each other, they are indeed a way to handle the very large temperature difference between the observed temperature at the beginning of the decomposition of austenite and $T_{\alpha}^{\circ}$ which was used as the reference temperature by these authors. As described in the introduction, part of this discrepancy is associated with the fact that the reference temperature should be $T_{\alpha}$ and not $T_{\alpha}^{\circ}$.

(2) Chang et al. replaced Eq. (3) giving the growth rate of the graphite nodule by an approximate mass balance, while Svensson et al. simply did not account for graphite growth. These differences are not significant because the growth of the graphite phase is in any case very limited.

(3) Chang et al. and Svensson et al. assumed that the composition of the austenite at the ferrite/austenite interface follows the metastable extrapolation of the $\alpha / \gamma$ boundary, i.e. that there is local equilibrium between these phases.

Since their preliminary works, Svensson and Wessén have developed a more detailed model for the decomposition of the austenite to ferrite and graphite. ${ }^{24)}$ They proposed to consider three successive steps:

(1) the formation of ferrite halos which is controlled by diffusion of carbon in the parent austenite as Venugopalan stated but did not describe. The authors assumed that ferrite nucleates $20 \mathrm{~K}$ below $T_{\alpha}^{0}$ and that the thickness of the halos which develop from these nuclei is constant as long as the halos are not totally formed.

(2) the growth of the ferrite shells controlled by an interfacial reaction at the graphite/ferrite interface which was found to depend on $\left(r^{\mathrm{g}}\right)^{-1}$.

(3) the growth of the ferrite shells controlled by diffusion of carbon through the ferrite phase.

\section{Development of a New Model}

All of the phenomena listed just above can actually affect the ferritic reaction and should thus be considered. In addition, as mentioned in the introduction, redistribution of carbon during cooling of the parent austenite should also be accounted for. This is the first feature described below; the ferritic and the pearlitic reactions are then successively considered accounting for the growth conditions detailed in the introduction. 


\subsection{Growth of Graphite from Austenite and Formation of the Ferrite Halos}

While the temperature of the material decreases below the eutectic reaction temperature, the solubility of carbon in austenite diminishes. Accordingly, the carbon content of the austenite phase should decrease and the graphite fraction should increase. It is assumed that the transfer of carbon from austenite to graphite depends only on diffusion of carbon in austenite and that local equilibrium holds at the austenite/graphite interface. The growth rate of the graphite nodules is given by:

$$
\rho^{\mathfrak{g}}\left(1-w_{\mathrm{C}}^{\gamma / \mathfrak{g}}\right) \frac{d r^{\mathfrak{g}}}{d t}=\rho^{\gamma} D_{\mathrm{C}}^{\gamma}\left|\frac{\partial w_{\mathrm{C}}^{\gamma}}{\partial r}\right|_{r \mathfrak{g}}
$$

where $w_{\mathrm{C}}^{\gamma / g}$ is the mass fraction of carbon in austenite at the austenite/graphite interface.

For simplicity, it is assumed that the carbon gradient at the interface may be expressed as $\left(\bar{w}_{\mathrm{C}}^{\gamma}-w_{\mathrm{C}}^{\gamma / \mathbf{g}}\right) / r^{\mathrm{g}}$, where $\bar{w}_{C}^{\gamma}$ is the average carbon content in austenite, and that the flux of carbon leads to a homogeneous decrease in the carbon content of the parent austenite. The change of $\bar{w}_{\mathrm{C}}^{\gamma}$ is thus given by:

$$
\frac{d \bar{w}_{\mathrm{C}}^{\gamma}}{d t} \approx-3 D_{\mathrm{C}}^{\gamma}\left(\bar{w}_{\mathrm{C}}^{\gamma}-w_{\mathrm{C}}^{\gamma / \mathrm{g}}\right) \frac{r^{\mathrm{g}}}{\left(r^{\circ}\right)^{3}-\left(r^{\mathrm{g}}\right)^{3}}
$$

The path followed by the average carbon content of austenite during cooling from $900^{\circ} \mathrm{C}$ was calculated for an alloy with $3.58 \mathrm{wt} \% \mathrm{C}$ and $2.57 \mathrm{wt} \% \mathrm{Si}$ (alloy $\mathrm{L} 1$ in Ref. 12)). The paths obtained for two cooling rates, 1 and $10 \mathrm{~K} / \mathrm{min}$, are shown with dotted lines in Fig. 3. The calculations were performed with the physical properties listed in the appendix. During preliminary calculations, it was found that the nodule count has a strong influence on $\bar{w}_{\mathrm{C}}^{\gamma}$. Thus, the surface nodule count measured on the sample of alloy L1 series D (in Ref. 12)) was used, namely $N_{\mathrm{A}}=330 \mathrm{~mm}^{-2}$. This value was converted to volume nodule count $N_{\mathrm{V}}^{\mathrm{o}}$ by means of the relation proposed by Castro ${ }^{25)}: N_{\mathrm{V}}^{\mathrm{o}}=3.46\left(N_{\mathrm{A}}\right)^{1.5}$, where $N_{\mathrm{V}}^{\mathrm{o}}$ and $N_{\mathrm{A}}$ are given respectively in $\mathrm{mm}^{-3}$ and $\mathrm{mm}^{-2}$.

It is observed in Fig. 3 that the average carbon content of the austenite phase is shifted to higher carbon contents with respect to the austenite/graphite boundary, although this shift decreases, as expected, when the cooling rate is decreased. Thus, the transformation of the bulk austenite to ferrite cannot proceed before the path followed by $\bar{w}_{C}^{y}$ has reached the metastable extrapolation of the austenite/ferrite boundary. The corresponding temperature will be noted $T_{\mathrm{h}}$ in the following. For the particular composition considered and for the two selected cooling rates, it is noted that $T_{\mathrm{h}}$ is above $T_{\alpha}$. It is worth to emphasize that the formation of the halos as described by Wessén and Svensson ${ }^{24)}$ could not begin before the temperature of the alloy is below $T_{\mathrm{h}}$; the reason is that it needs diffusion of carbon in austenite which cannot proceed as long as $w_{c}^{\gamma / \alpha}$ is lower than $\bar{w}_{C}^{\gamma}$. Also, according to the present calculation, the temperature difference $T_{\alpha}^{\mathrm{o}}-T_{\mathrm{h}}$ for the nucleation of ferrite depends on the cooling rate and cannot be considered as a constant. Moreover, the thickness of the halos should increase during their formation, particularly when the

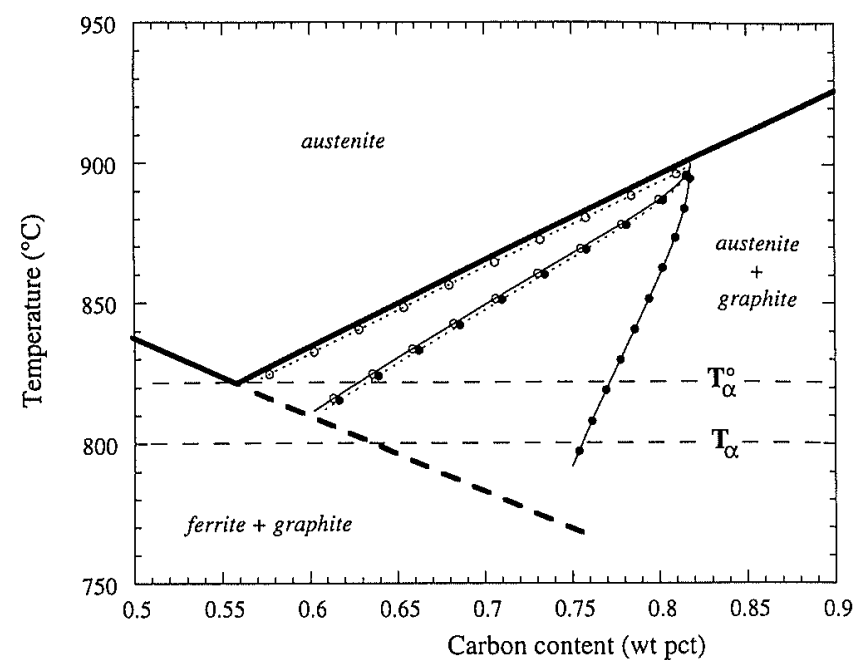

Fig. 3. Calculated path followed by the average composition of austenite during cooling from $900^{\circ} \mathrm{C}$ for two cooling rates, $1 \mathrm{~K} / \mathrm{min}$ (empty circles) and $10 \mathrm{~K} / \mathrm{min}$ (full circles). Calculations were made for the selected value of $D_{\mathrm{C}}^{\gamma}$ (dotted lines) and for the corrected one (full lines), see text.

temperature of the alloy falls below $T_{\alpha}$. Thus, the applicability of the model developed by Wessén and Svensson for this stage of the ferritic reaction is quite limited. Under low cooling rates, it can be considered that the growth of the halos will represent a short part of the transformation because there will be enough time for diffusion of carbon; on the opposite, at higher cooling rates, the formation of the halos will be made quicker because of the nucleation of a large number of ferrite grains around each nodule. It was thus decided to follow the lines of other authors and to consider that the halos form instantaneously when ferrite nucleates, but to consider that this happens only when the temperature $T_{\mathrm{h}}$ is reached. In addition, according to the conditions described in the introduction, the ferritic reaction can proceed only when the temperature of the alloy is below $T_{\alpha}$ and when the growth rate given by Eq. (2) is positive. This growth is described below.

\subsection{The Ferritic Reaction}

As previously proposed, ${ }^{24)}$ it is considered that the growth of graphite inside the ferrite shell may be partly controlled by an interfacial reaction. On the other hand, local equilibrium is assumed at the ferrite/austenite interface, so that the carbon content in each phase at this interface is given by the extrapolation of the relevant boundary in the $\mathrm{Fe}-\mathrm{C}$ section. The value of $\Delta w_{\mathrm{C}}$ which drives the transfer of carbon atoms from the ferrite/austenite to the ferrite/graphite interface is thus $\Delta w_{C}=w_{C}^{\alpha / \gamma}-w_{C}^{\mathrm{i}}$, where $w_{C}^{\mathrm{i}}$ is the actual carbon content in ferrite at the interface with graphite. The growth rate of ferrite is obtained by applying Eq. (2) below $T_{\alpha}$. Actual growth of ferrite is however subjected to the condition that the growth rate given by Eq. (2) is positive. The composition gradients in Eq. (2) are expressed by:

$$
\left|\frac{\partial w_{\mathrm{C}}^{\alpha}}{\partial r}\right|_{r^{\alpha}}=\frac{r^{\mathrm{g}} \Delta w_{\mathrm{C}}}{r^{\alpha}\left(r^{\alpha}-r^{\mathrm{g}}\right)} \text { and }\left|\frac{\partial w_{\mathrm{C}}^{\gamma}}{\partial r}\right|_{r^{\alpha}}=\frac{\bar{w}_{\mathrm{C}}^{\gamma}-w_{\mathrm{C}}^{\gamma / \alpha}}{r^{\alpha}}
$$


When the overall growth rate given by Eq. (2) is negative, diffusion of carbon from austenite to graphite and change of the average carbon content of austenite are calculated as before. Further cooling of the metal drives the system at a temperature where the growth rate of ferrite becomes positive. Then, the redistribution of carbon in austenite becomes negligible with respect to the transfer of carbon through ferrite as pointed out by Venugopalan, ${ }^{20)}$ and the reaction is now controlled only by the transfer of carbon atoms through the ferrite shell. The corresponding flux density of carbon $\Phi$ may be expressed as:

$$
\Phi=-\rho^{\mathrm{g}}\left(1-w_{\mathrm{C}}^{\mathrm{i}}\right) \frac{d r^{\mathrm{g}}}{d t}
$$

It is proposed to describe this transfer as two steps in series, thus following an approach applied previously to the deposition of primary graphite from the liquid. ${ }^{26}$ ) The flux of carbon atoms is the same for the two steps but is written:

$$
\Phi=-K^{\alpha} \rho^{\alpha}\left(w_{\mathrm{C}}^{\mathrm{i}}-w_{\mathrm{C}}^{\alpha / \mathrm{g}}\right)^{2} \quad \text { for the interfacial reaction }
$$

where $K^{\alpha}$ is a constant which characterizes the interfacial process;

$$
\Phi=-\rho^{\alpha} D_{\mathrm{C}}^{\alpha}\left|\frac{\partial w_{\mathrm{C}}^{\alpha}}{\partial r}\right|_{r \varepsilon} \text { for the diffusion process .... }
$$

where the composition gradient is given by Eq. (4) with $\Delta w_{\mathrm{C}}=w_{\mathrm{C}}^{\alpha / \gamma}-w_{\mathrm{C}}^{\mathrm{i}}$.

Equating expressions (10) and (11) of the flux gives:

$$
w_{\mathrm{C}}^{\mathrm{i}}=w_{\mathrm{C}}^{\alpha / g}+\Lambda \text { and } \Phi=-\rho^{\alpha} \frac{D_{\mathrm{C}}^{\alpha}}{\bar{r}}\left(w_{\mathrm{C}}^{\alpha / \gamma}-w_{\mathrm{C}}^{\alpha / \mathrm{g}}-\Lambda\right)
$$

with

$$
\begin{gathered}
A=\sqrt{\left\{\frac{D_{\mathrm{C}}^{\alpha}}{2 K^{\alpha} \bar{r}}\right\}^{2}+\frac{D_{\mathrm{C}}^{\alpha}}{K^{\alpha} \bar{r}}\left(w_{\mathrm{C}}^{\alpha / \gamma}-w_{\mathrm{C}}^{\alpha / \mathrm{g}}\right)}-\frac{D_{\mathrm{C}}^{\alpha}}{2 K^{\alpha} \bar{r}} \text { and } \\
\bar{r}=\frac{r^{\mathrm{g}}\left(r^{\alpha}-r^{\mathrm{g}}\right)}{r^{\alpha}}
\end{gathered}
$$

The growth rate of the ferrite shell is readily calculated by applying Eq. (2) while the growth rate of the graphite nodule is obtained by inserting the above expression of the flux $\Phi$ in Eq. (9). Given the growth rate of the ferrite shell, and neglecting the bulging effect associated with graphite growth, the change with time of the volume fraction $g^{\alpha s}$ of the eutectoid spheres (graphite plus ferrite) is given by:

$$
\frac{d g^{\alpha \mathrm{s}}}{d t}=N_{\mathrm{v}}^{\mathrm{o}}\left(1-g^{t}\right) 4 \pi\left(r^{\alpha}\right)^{2} \frac{d r^{\alpha}}{d t}
$$

where $\left(1-g^{t}\right)$ is the volume fraction of untransformed austenite which varies between 1 and 0 during the eutectoid reaction and is introduced to account for impingement.

\subsection{The Pearlitic Reaction}

Once the temperature $T_{\mathrm{p}}$ for the metastable transformation has been reached, pearlite $\mathrm{co}^{+}$ies may nucleate

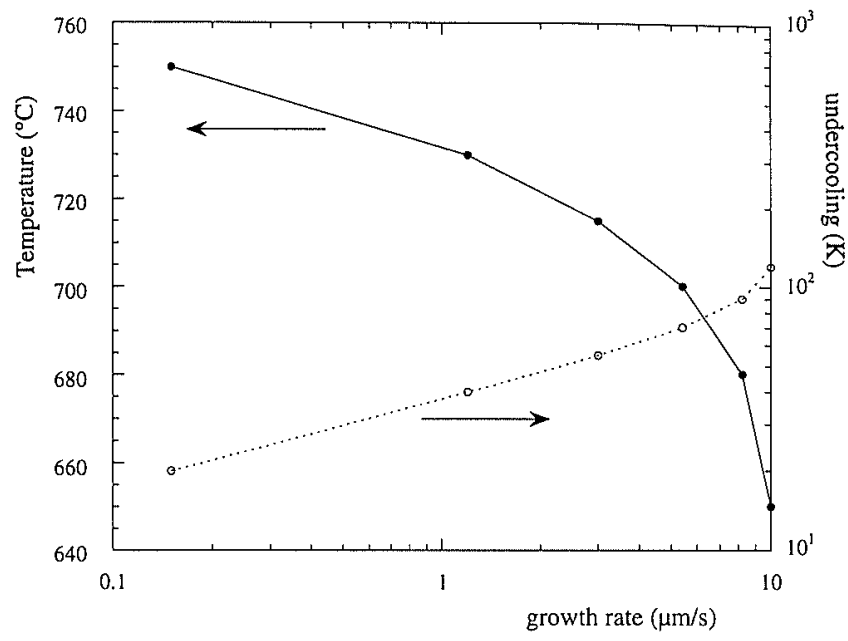

Fig. 4. Plot of the experimental growth rate of pearlite in $\mathrm{Fe}-\mathrm{C}-2 \%$ Si steel (after Al Salman et $a .^{16)}$ ), expressed in terms of temperature (solid curve with dark circles) and of the undercooling $\Delta T_{\mathrm{p}}=T_{\mathrm{p}}-T$ (dotted lines with empty circles), with $T_{\mathrm{p}}=770^{\circ} \mathrm{C}$.

and grow. Both steps have been considered. Nucleation was assumed to be described by the following law:

$$
\begin{gathered}
d N_{\mathrm{V}}^{\mathrm{p}}=A_{\mathrm{p}}\left(N_{\mathrm{V}}^{\mathrm{o}}-N_{\mathrm{v}}^{\mathrm{p}}\right)\left(1-g^{\mathrm{t}}\right)\left(\Delta T_{\mathrm{p}}\right)^{m} d\left(\Delta T_{\mathrm{p}}\right) \\
\text { for } \Delta T_{\mathrm{p}}>0 \text { and } \\
d N_{\mathrm{v}}^{\mathrm{p}}=0 \text { for } \Delta T_{\mathrm{p}}<0
\end{gathered}
$$

where $N_{\mathrm{V}}^{\mathrm{p}}$ is the number of pearlite colonies, $m$ and $A_{\mathrm{p}}$ are constants which define the nucleation law, and $\Delta T_{\mathrm{p}}$ is the undercooling with respect to $T_{\mathrm{p}}, \Delta T_{\mathrm{p}}=T_{\mathrm{p}}-T$. Nucleation stops when the number of pearlite colonies equals the number of graphite nodules.

Isolated pearlite colonies are assumed spherical in shape. At each step and before the growth calculation, the radius of the pearlite colonies is recalculated in such a way that the total volume fraction of pearlite is left unchanged by the new nucleation events. As emphasized in the introduction, growth of pearlite in cast irons is expected to follow the same laws than in steels, and more particularly those valid for silicon steels. The growth rates measured by $\mathrm{Al}$ Salman et $a .^{16)}$ in the case of an eutectoid $\mathrm{Fe}-\mathrm{C}-2 \% \mathrm{Si}$ steel were thus selected. They have been plotted in Fig. 4, where they are expressed both versus temperature and versus $\Delta T_{\mathrm{p}}$, with $T_{\mathrm{p}}$ equal to $770^{\circ} \mathrm{C}$ for the particular alloy studied by these authors (see appendix). For undercoolings up to $100 \mathrm{~K}$, the following relationship between the growth rate of a given pearlite colony and $\Delta T_{\mathrm{p}}$ applies:

$$
\frac{d r^{\mathrm{p}}}{d t}=1.63 \times 10^{-5}\left(\Delta T_{\mathrm{p}}\right)^{3} \quad \mu \mathrm{m} \cdot \mathrm{s}^{-1}
$$

In the calculations described below, it was assumed that this growth law applies also to alloys with a slightly different level of Si.

The change of the pearlite fraction is then given by:

$$
\frac{d g^{\mathrm{p}}}{d t}=N_{\mathrm{v}}^{\mathrm{p}}\left(1-g^{t}\right) 4 \pi\left(r^{\mathrm{p}}\right)^{2} \frac{d r^{\mathrm{p}}}{d t}
$$

and the fraction of transformed austenite calculated with respect to the initial volume of austenite is: 


$$
g^{i}=\frac{\left(g^{\alpha \mathrm{s}}+g^{\mathrm{p}}\right)}{\left(1-g^{\mathrm{g}}\right)}
$$

Further indications on the procedure followed to make the calculations as well as the selected thermophysical data are given in the appendix.

\section{Results}

The calculations described below were intended at reproducing the kinetics of austenite decomposition previously estimated from DTA records. ${ }^{12)}$ The samples were heated to $1100^{\circ} \mathrm{C}$ for one hour and then cooled at a controlled rate down to $600^{\circ} \mathrm{C}$, then reheated to $900^{\circ} \mathrm{C}$ for $10 \mathrm{~min}$ before being cooled down to $600^{\circ} \mathrm{C}$ at another rate and reheated again to $900^{\circ} \mathrm{C}$ for $10 \mathrm{~min}$ and cooled at a different rate. Two samples will be considered here (the notation used is that of Ref. 12)): (i) sample $\mathrm{C}$ was cooled successively at 10,5 and $1 \mathrm{~K} / \mathrm{min}$, and had a nodule count of $190 \mathrm{~mm}^{-2}$; (ii) sample D was cooled successively at 20,10 and $2 \mathrm{~K} / \mathrm{min}$, and had a nodule count equal to $330 \mathrm{~mm}^{-2}$.

The heat transfer in the DTA cell was simulated by means of a simple model described in the appendix. A number of calculations were performed to investigate the effect on the kinetics of the ferritic reaction of the two input data, namely the kinetics coefficient $K^{\alpha}$, and the initial thickness of the ferrite halo, $\delta r^{\alpha}$. This was done by comparing the calculated curves with the experimental ones. The value of $K^{\alpha}$ affects the shape of the curves during the whole transformation while the value of $\delta r^{\alpha}$ acts only at the beginning of the ferritic reaction. It was thus possible to find a good estimate of $K^{\alpha}$ by comparing the slope of the transformation curve at intermediate values of $g^{t}$. The value finally selected was $4.0 \times 10^{-2} \mathrm{~K} \mathrm{~m}^{-1}$. Then, it was found convenient to set $\delta r^{\alpha}$ equal to $0.1 \mu \mathrm{m}$. In the calculations to be presented below, the value used for the constants of the nucleation law of pearlite were estimated from the experiments at the highest cooling rates: $m=3$ and $A_{\mathrm{p}}=10^{-1} \mathrm{~m}^{-3} \mathrm{~K}^{-4}$ but they cannot be considered to be firmly established.

Figure 5 compares the evolution of the fraction of transformed austenite as calculated (dotted lines) and as experimentally estimated (full lines) upon both coolings of sample D from $900^{\circ} \mathrm{C}$. The calculated curves show a shift towards lower temperature when the cooling rate is increased. Moreover, we can see that the effect of the cooling rate on the kinetics of phase transformation is satisfactorily described. However, the curves in Fig. 5 show that the effect of the cooling rate on the onset of the austenite decomposition is not properly described. At first, one thought that this could be due to the nucleation step of ferrite which was not described. A model accounting for it was developed in which the size of the eutectoid spheres was calculated for all the size classes defined by the successive nucleation events. It was found that when the start of the reaction was appropriately described, the bulk transformation was not. In other words, the discrepancy related to the onset of the transformation could not be due to the nucleation kinetics of ferrite. It became evident that the temperature

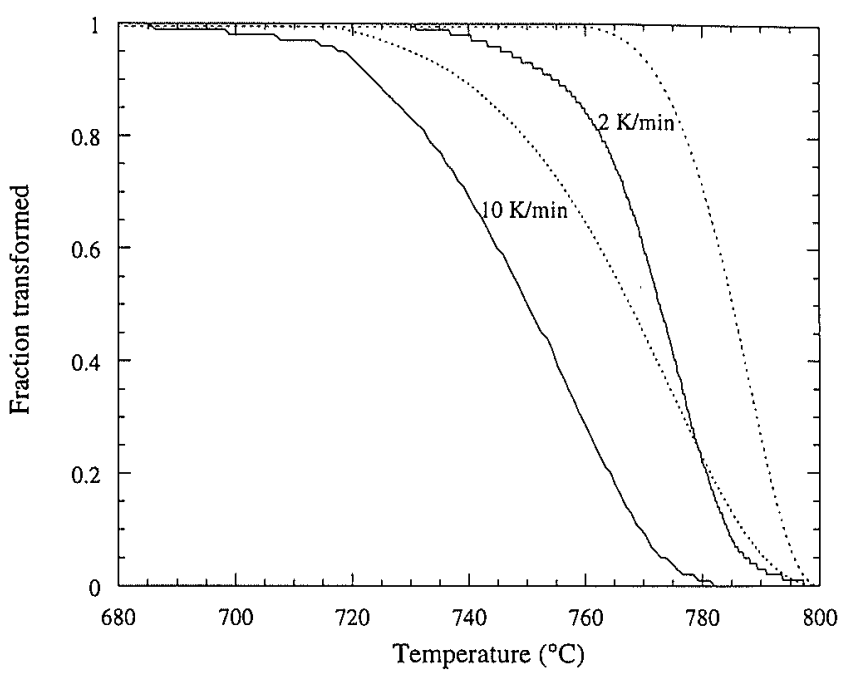

Fig. 5. Comparison of calculated (dotted lines) and experimental (solid lines) curves of transformed austenite in the case of sample $D$ with a nodule count of $330 \mathrm{~mm}^{-2}$, cooled from $900^{\circ} \mathrm{C}$ at 2 and $10 \mathrm{~K} / \mathrm{min}$. Calculations were made with the selected value of $D_{\mathrm{C}}^{\gamma}$.

$T_{\mathrm{h}}$ was not correctly predicted, i.e. that the change of the carbon content in austenite was not conveniently described.

In fact, Hiller ${ }^{27)}$ showed in the case of white cast irons that the graphitization process is not simply controlled by volume diffusion of carbon in austenite; as the size of the graphite nodules increases, the transfer of carbon is successively controlled by diffusion of iron, creep of the matrix and finally diffusion of carbon. The first two steps are related to transformation rates much lower than the one corresponding to the third step, by a factor in between five to ten. ${ }^{28)}$ It was thus considered that the transfer of carbon could be estimated by considering a corrected diffusion coefficient of carbon in austenite, and it was found that $D_{C}^{\gamma}$ should be divided by 10 . The path followed by $\bar{w}_{c}^{\gamma}$ during cooling at 1 and $10 \mathrm{~K} / \mathrm{min}$ thus calculated is shown with solid lines in Fig. 3 . It is seen that the sensitivity to the cooling rate is increased and that the temperature $T_{\mathrm{h}}$ is lower than in the former calculations. At the $10 \mathrm{~K} / \mathrm{min}$ cooling rate, the curve ends before the $\gamma / \alpha$ boundary because the pearlitic reaction begins.

Figures 6 and 7 present the calculations of the transformation kinetics made for samples C (Fig. 5) and $\mathrm{D}$ (Fig. 6) with the corrected value of the diffusion coefficient of carbon in austenite. In both figures, we notice that there is a shift to higher temperatures of most of the calculated curves with respect to the experimental ones. This shift increases with the cooling rate, it is related to the simplicity of the heat transfer model of DTA described in the appendix. In fact, there is a delay between the beginning of the reaction in the sample and the recording of the corresponding thermal arrest. This delay is of the order of $\theta$ (the time constant characteristic of the transfer function between the sample and the thermocouple) at the beginning of the transformation and then decreases. The value of $\theta$ was found of the order of $60 \mathrm{~s}^{10)}$ for the DTA apparatus used in this study. Using this value, the predicted shift of the curves for a 


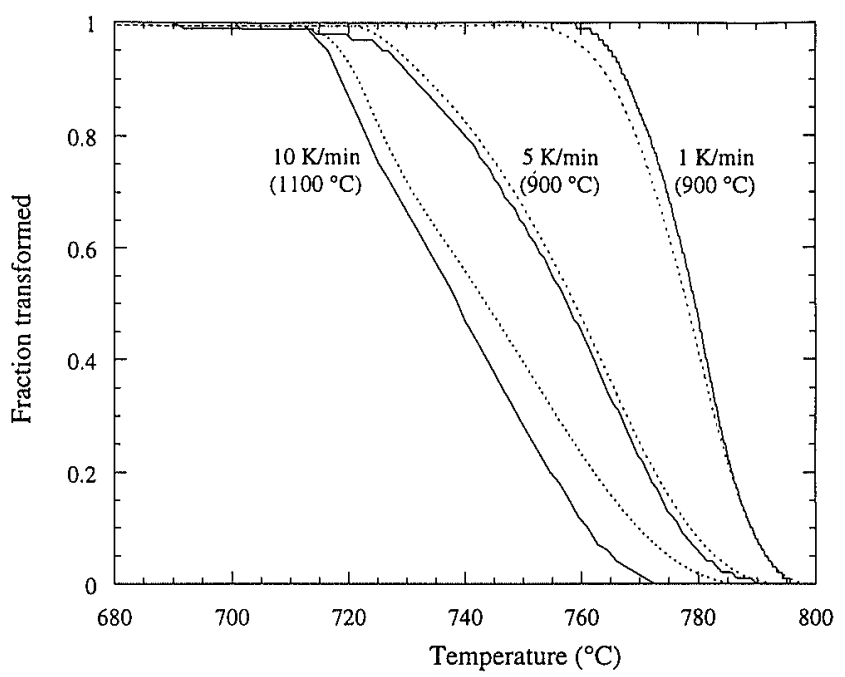

Fig. 6. Comparison of calculated (dotted lines) and experimental (solid lines) curves of transformed austenite in the case of sample $C$ with a nodule count of $190 \mathrm{~mm}^{-2}$. Calculations were made with the corrected value of $D_{C}^{\gamma}$. The relevant cooling rate is indicated on each curve, with the starting temperature between brackets.

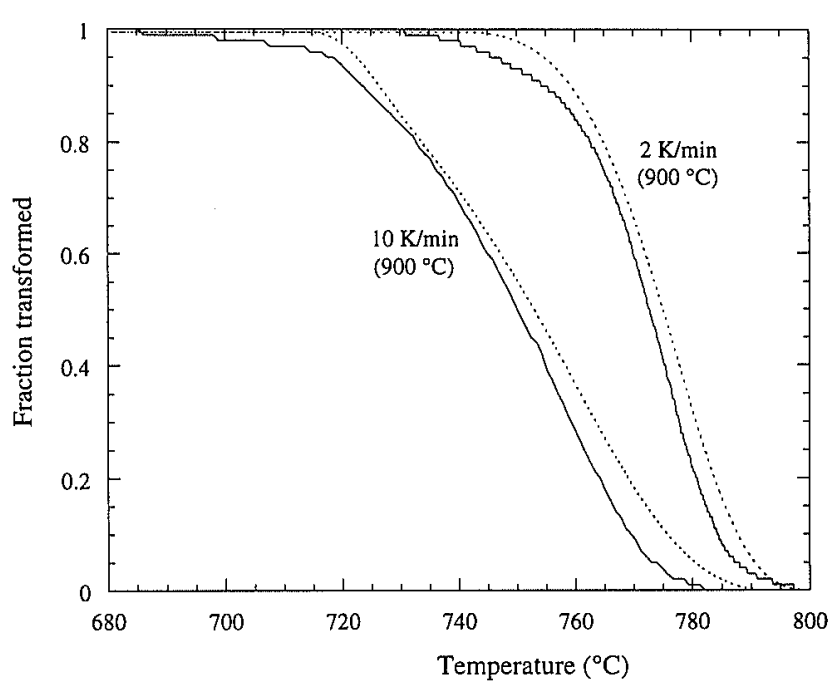

Fig. 7. Comparison of calculated (dotted lines) and experimental (solid lines) curves of transformed austenite in the case of sample $D$ with a nodule count of $330 \mathrm{~mm}^{-2}$. Calculations were made with the corrected value of $D_{\mathrm{C}}^{\gamma}$. The relevant cooling rate is indicated on each curve, with the starting temperature between brackets.

$10 \mathrm{~K} / \mathrm{min}$ cooling rate is at most $10 \mathrm{~K}$ at the beginning of the transformation, in good agreement with the discrepancy observed in Figs. 5 and 6. Nevertheless, owing to the various simplifications introduced in the physical model of the eutectoid transformation, as well as in the heat transfer model, Figs. 6 and 7 show that the effect of the cooling rate on the onset of the transformation as well as on the overall kinetics is conveniently reproduced by the model proposed.

The present model has been developed and illustrated with Fe-C-Si alloys with spherical graphite, but could be easily extended to alloys with low level additions of pearlite promoter elements. There are however two main drawbacks that should be emphasized. First, it is expected that microsegregation of substitutional solutes could affect the transformation. It has been shown previously that this effect should be small in the case of $\mathrm{Fe}-\mathrm{C}-\mathrm{Si}$ alloys except in the last $20 \%$ of the transformation. ${ }^{29)}$ In addition, it could be difficult to separate the contributions of impingement and of microsegregation in this domain of high transformed volume fraction. On the other hand, one may wonder about the possible influence of stresses during the ferritic reaction. It is in fact quite possible that the eutectoid transformation depends also on stresses due to the difference in the densities of graphite and ferrite. This could explain why Wessén and Svensson ${ }^{24)}$ found that the kinetics constant they introduced to describe the transfer of carbon atoms from ferrite to graphite decreases with the nodule size. However, there is no doubt that interfacial reactions at the graphite matrix interface affects the growth of ferrite in cast iron. This is clearly established by the fact that grey irons with lamellar graphite are much less prone to give a ferritic matrix than spheroidal or compacted graphite cast iron. ${ }^{30)}$ Thus, the approach followed by Wessén and Svensson and in the present work should be refined to separate the two contributions, the interfacial reaction and the effect of stresses and strains.

\section{Conclusion}

A model of the eutectoid reaction during cooling of Fe-C-Si alloys with spheroidal graphite has been presented. It is based on a description of the growth conditions of ferrite in the stable system and of pearlite in the metastable one. The transfer of carbon from ferrite to graphite during the ferritic reaction was described by physical laws which take into account an interfacial reaction at the ferrite/graphite interface as well as volume diffusion of carbon through the ferrite halos. The pearlitic reaction accounts for nucleation and growth of pearlite colonies. The characteristics of the nucleation law of pearlite have been determined so as to fit the experimental data while the growth rate of pearlite was expressed according to experimental data available in the literature. To reproduce the effect of the cooling rate at the beginning of the austenite decomposition, it appeared of first importance to describe the redistribution of carbon between austenite and graphite before the beginning of the eutectoid reaction. Calculations showed that this stage should be controlled by stress effects and it was found necessary to use an apparent diffusion coefficient of carbon in austenite. In this line, work is going on in order to characterize the possible effect of stresses and strains on the ferritic reaction.

\section{Acknowledgement}

This work has received a financial support from Péchiney-Electrométallurgie.

\section{REFERENCES}

1) R. Elliott: Cast Iron Technology, Butterworths et Co., London, (1988).

2) D. R. Askeland and S. S. Gupta: AFS Trans., 83 (1975), 217.

3) E. N. Pan, M. S. Lou and C. R. Loper: AFS Trans., 87 (1979), 819. 
4) W. C. Johnson and B. V. Kovacs: Metall. Trans. A, 9A (1978), 219.

5) B. V. Kovacs: AFS Trans., 88 (1980), 79.

6) R. B. Gundlach and E. P. Whelan: AFS Trans., 100 (1992), 713

7) J. M. Schissler: Hommes Fonderie, 4 (1986), 13.

8) E. Dorazil: High Strength Austempered Ductile Cast Iron, Ellis Horwood, (1991).

9) K. Ogi, A. Sawamoto, Y. C. Jin and C. R. Loper: AFS Trans., 96 (1988), 75.

10) J. Lacaze, S. Ford, C. Wilson and E. Dubu: Scand. J. Metall., 22 (1993), 300

11) U. Ekpoom and R. W. Heine: AFS Trans., 86 (1978), 281

12) J. Lacaze, C. Wilson and C. Bak: Scand. J. Metall., 23 (1994), 151.

13) J. Lacaze, A. Boudot, V. Gerval, D. Oquab and H. Santos: Metall. Mater. Trans. A, 28A (1997), 2015.

14) M. Hillert: Monograph $n^{\circ} 33$, The Inst. of Metals, London, (1968), 231.

15) S. K. Tewari and R. C. Sharma: Metall. Trans. A, 16A (1985), 597.

16) S. A. Al Salman, G. W. Lorimer and N. Ridley: Acta Metall., 27 (1979), 1391

17) D. Venugopalan: AFS Trans., 97 (1989), 271

18) B. F. Brown and M. F. Hawkes: AFS Trans., 59 (1951), 181.

19) D. Venugopalan: Metall. Trans., 21A (1990), 913.

20) D. Venugopalan: Conf. Proc. Cast Iron IV, MRS, (1990), 271.

21) T. Owadano, T. Nishimura, H. Miyata and Y. Kubo: Trans. Jpn. Inst. Met., 16 (1975), 663.

22) S. Chang, D. Shangguan and D. M. Stefanescu: Metall. Trans., 23A (1992), 1333.

23) I. L. Svensson, M. Wessén and A. Gonzalez: Conf. Proc. MCWASP VI, TMS, (1993), 29.

24) M. Wessén and I. L. Svensson: Metall. Trans., 27A (1996), 2009.

25) M. Castro: PhD thesis, INPL, Nancy, France, (1991).

26) J. Lesoult, M. Castro and J. Lacaze: Acta Metall. Mater., 46 (1998), 983.

27) M. Hillert: Jernkontorets Ann., 141 (1957), 67.

28) C. E. Birchenall and H. W. Mead: J. Met., (1956), 1004.

29) V. Gerval and J. Lacaze: Proc. of the Conf. SP97, ed. by J. Beech and H. Jones, 506

30) R. C. Voigt and R. C. Loper: AFS Trans., 97 (1989), 595.

3I) B. Sundman, B. Jansson and J. O. Andersson: Calphad, 9 (1985), 150.

32) B. Uhrenius: Hardenability Concepts with Application to Steel, The Met. Soc. of AIME, (1977), 28.

33) Z. K. Liu and J. Agren: Acta Metall, 37 (1989), 3157.

34) J. Agren: Acta Metall., 30 (1982), 84I.

35) I. Barin: Thermochemical Data of Pure Substances, VCH, Weinheim, (1993)

36) A. T. Dinsdale: NPL Report DMA(A) 195, (1989).

\section{Appendix. Thermophysical Data}

Description of the Phase Diagram

The following expressions, where the Si content in austenite, $w_{\mathrm{S}}$, is given in mass fraction, and the temperature $T$ in Celsius, have been obtained by fitting to calculations made with the Thermocalc software ${ }^{31)}$ using the data of Uhrenius. ${ }^{32}$

$$
\begin{aligned}
& w_{\mathrm{C}}^{\gamma / \alpha}= 0.1876-4.112 \cdot 10^{-4} T+2.26 \cdot 10^{-7} T^{2}+0.125 w_{\mathrm{Si}} \\
& w_{\mathrm{C}}^{\alpha / \gamma}= 6.7 \cdot 10^{-4}-5 \cdot 10^{-10} T^{2}-2.8 \cdot 10^{-7} T \\
&+\left(1.2 \cdot 10^{-8} T^{2}-4.5 \cdot 10^{-3}\right) w_{\mathrm{Si}} \\
& \Delta w_{\mathrm{C}}= \Delta T\left(2.9 \cdot 10^{-6}-2.8 \cdot 10^{-5} w_{\mathrm{Si}}\right) \\
& w_{\mathrm{C}}^{\alpha / g}= w_{\mathrm{C}}^{\alpha / \gamma}-\Delta w_{\mathrm{C}} \\
& T_{\alpha}^{\circ}\left({ }^{\circ} \mathrm{C}\right)=739+3150 w_{\mathrm{Si}} \\
& T_{\alpha}\left({ }^{\circ} \mathrm{C}\right)=739+1840 w_{\mathrm{Si}}+20000\left(w_{\mathrm{Si}}\right)^{2}
\end{aligned}
$$

$$
\begin{aligned}
& T_{\mathrm{p}}^{\mathrm{o}}\left({ }^{\circ} \mathrm{C}\right)=727+3007 w_{\mathrm{Si}}-19800\left(w_{\mathrm{Si}}\right)^{2} \\
& T_{\mathrm{p}}\left({ }^{\circ} \mathrm{C}\right)=727+2160 w_{\mathrm{Si}}+230\left(w_{\mathrm{Si}}\right)^{2}
\end{aligned}
$$

Care must be taken that the actual average content of $\mathrm{Si}$ in austenite is higher than the nominal Si content of the alloy because of the graphite fraction. One has:

$$
w_{\mathrm{Si}}=w_{\mathrm{Si}}^{\mathrm{o}} \frac{\rho^{\mathrm{g}} g^{\mathrm{gra}}+\rho^{\gamma}\left(1-g^{\mathrm{gra}}\right)}{\rho^{\gamma}\left(1-g^{\mathrm{gra}}\right)}
$$

where $w_{\mathrm{Si}}^{\circ}$ is the nominal silicon content of the alloy.

The initial carbon content of austenite was given by the equilibrium value with the austenite/graphite solvus expressed as a line joining the eutectoid point to the point representing the austenite at the eutectic temperature. The eutectic temperature, $T_{\mathrm{EG}}$, and the carbon content at the eutectic, $w_{\mathrm{C}, \mathrm{EG}}$, were calculated according to the following formula:

$$
\begin{aligned}
& T_{\mathrm{EG}}=1154+425 w_{\mathrm{Si}}^{\circ} \\
& w_{\mathrm{C}, \mathrm{EG}}=k_{\mathrm{C}}\left(0.0434-28 w_{\mathrm{Si}}^{\circ}\right)
\end{aligned}
$$

where $k_{\mathrm{C}}$ is the partition coefficient of carbon between austenite and liquid, set equal to 0.47 .

\section{Diffusion Coefficients}

The diffusion coefficients (given in $\mathrm{m}^{2} \mathrm{~s}^{-1}$, with $T$ expressed in Kelvin) used in the present work are those selected by Liu and Agren ${ }^{33)}$ and Agren ${ }^{34)}$ respectively:

$$
\begin{aligned}
D_{\mathrm{C}}^{\gamma} & =2.343 \cdot 10^{-5} \exp \left(-\frac{17767}{T}\right) \\
D_{\mathrm{C}}^{\alpha} & =2.0 \cdot 10^{-6} \exp \left(-\frac{10115}{T}\right) \\
& \cdot \exp \left\{0.5898\left[1+\frac{2}{\pi} \arctan \left(\frac{15629}{T_{\mathrm{C}}}-\frac{15309}{T}\right)\right]\right\}
\end{aligned}
$$

where $T_{\mathrm{C}}$ is the Curie temperature, which is here calculated according to the following approximate formulae which was evaluated from the binary $\mathrm{Fe}-\mathrm{Si}$ diagram: $T_{\mathrm{C}}(\mathrm{K})=1043-1000 w_{\mathrm{Si}}$

\section{Heat Transfer Calculation}

DTA experiments were performed on a SETARAM 2000 set up with alumina as reference body. The sample and the reference were placed in alumina crucibles $7 \mathrm{~mm}$ high and $4 \mathrm{~mm}$ of inner diameter. For modelling heat transfer, it was assumed that the temperature of the alloy sample and of the reference are homogeneous. The heat balance equation for the sample was written in the following way:

$$
\rho^{\mathrm{m}} V C_{\mathrm{p}}^{\mathrm{m}} \frac{d T_{\mathrm{s}}}{d t}=-A h\left(T_{\mathrm{s}}-T_{\mathrm{f}}\right)+\rho^{\mathrm{m}} V \frac{d g}{d t} \Delta H
$$

where $\rho^{\mathrm{m}}$ and $C_{\mathrm{p}}^{\mathrm{m}}$ are the density and the heat capacity of the alloy, $T_{\mathrm{s}}$ and $T_{\mathrm{f}}$ are the temperature of the sample and of the furnace, $g$ is the fraction transformed (which varies between 0 and $1-g^{\mathrm{gra}}$ ), $\Delta H$ is the heat of transformation, $V$ and $A$ are the volume and the area of the crucibles.

The same equation without the last term in the right hand side applies to the sample when it does not undergo any phase change. A similar equation without the last 
term in the right hand side may also be written for the reference body. Simulations were performed with an explicit scheme by calculating the temperature of the sample and of the reference by means of the above equation for preselected time steps. The value of the change of the transformed fraction calculated as described in the text was inserted when appropriate. Because of the fact that the sample and reference thermocouples are located below the related crucibles, the temperature they record differs slightly from the one inside the crucible. This difference is expected to increase with the cooling rate. At the very beginning of the transformation, it is of the order of $V_{\mathrm{r}} \cdot \theta$, where $V_{\mathrm{r}}$ is the cooling rate and $\theta$ is the time constant of the transfer function of the DTA apparatus (about $60 \mathrm{~s}$ in the present case $^{10)}$ ), and then decreases.

The selected value of the density of ferrite, austenite, graphite and $\mathrm{Al}_{2} \mathrm{O}_{3}$ were respectively: $7800,7900,2200$ and $4000 \mathrm{~kg} \cdot \mathrm{m}^{-3}$. The heat capacity for $\mathrm{Al}_{2} \mathrm{O}_{3}$ was given as $1185+0.1617 \times(T-500) \mathrm{J} \cdot \mathrm{kg}^{-1} \cdot \mathrm{K}^{-1}$ which fits reasonably well the assessed data $^{35)}$ in the temperature range 650 to $1200^{\circ} \mathrm{C}$. The heat capacity of the metal was calculated by a simple additivity rule:

$$
C_{\mathrm{p}}^{\mathrm{m}}=f^{\text {gra }} C_{\mathrm{p}}^{\mathrm{gra}}+f^{\gamma} C_{\mathrm{p}}^{\gamma}+f^{\alpha} C_{\mathrm{p}}^{\alpha}
$$

where $C_{\mathrm{p}}^{\alpha}$ and $C_{\mathrm{p}}^{\gamma}$ were evaluated using the data of pure $\mathrm{Fe}$ assessed by Dinsdale ${ }^{36)}$ and where $f^{\varphi}$ is the mass fraction of phase $\varphi$. The sharp change of the heat capacity of ferrite due to the magnetic ordering at the Curie temperature was taken into account for ferrite and was neglected for pearlite.

The geometric modulus $V / A$ of the crucibles was set to $10^{-3} \mathrm{~m}$ and the value of $h$ to $250 \mathrm{~J} \cdot \mathrm{m}^{-2} \cdot \mathrm{K}^{-1} \cdot \mathrm{s}^{-1}$ for both the sample and reference crucibles. Although experiments ${ }^{12)}$ showed that the value of $h$ could vary slightly from one experiment to another, it was left unchanged for all the calculations presented in this paper. Indeed, the calculated kinetics are not highly sensitive to its exact value. The transformation enthalpy was set equal to $58 \mathrm{~kJ} \cdot \mathrm{kg}^{-1}$ for both the stable and metastable transformations. 